\title{
RELAÇÕES DE GÊNERO E PRECARIZAÇÃO DO TRABALHO DOCENTE
}

\author{
Edson Caetano - UFMT \\ caetanoedson@ hotmail.com ${ }^{1}$
}

\author{
Camila Emanuella Pereira Neves -UFMT \\ camilaemanuella@ hotmail.com²
}

\section{RESUMO:}

$\mathrm{O}$ artigo pretende discutir a trajetória das mulheres no exercício do magistério relacionando-a com o mundo do trabalho e, assim, ampliar os olhares sobre a constituição da profissão docente. Na busca por uma maior inserção no mercado de trabalho, a mulher, através de lutas, avançou e recuou em momentos distintos, mas acabou por conquistar espaço e identidade profissional. A feminização da profissão docente é vista como um dos fatores de desvalorização profissional da carreira docente. Atualmente, uma parcela considerável das professoras manifesta insatisfação com a docência, em razão da crescente desvalorização da profissão, dos baixos salários e das precárias condições de trabalho. $\mathrm{O}$ texto pretende, ainda, discutir as interferências promovidas pela reestruturação do trabalho pedagógico no sentido da flexibilização e precarização do trabalho docente.

Palavras-Chave: feminização do trabalho docente, trabalho docente, educação e trabalho.

\section{RELATIONSHIP OF GENDER AND PRECARIOUSNESS LABOR TEACHER}

\begin{abstract}
:
The article will discuss the history of women in the exercise of teaching relates to the world of work and thus broaden their eyes on the establishment of the teaching profession. In the search for greater integration into the labor market, women, through struggles, advanced and retreated at different times, but eventually conquer space and professional identity. The feminization of the teaching profession is seen as one of the factors of professional devaluation of the teaching profession. Currently, a considerable part of teachers expressed dissatisfaction with teaching, due to the increasing devaluation of the profession, the low wages and poor working conditions. The text also discusses the interferences promoted for the reorganization of the pedagogical work in the direction of the flexibilization and precariousness of the teacher's work.
\end{abstract}

Key-Words: feminization of the teacher's work, teacher's work, education and work.

\section{INTRODUÇÃO}

Diante da constituição atual do quadro de docentes, predominantemente feminino, procuramos elencar subsídios que nos auxiliem a refletir e compreender a constituição, as reivindicações, as conquistas, os desafios, as condições de trabalho, as angústias que marcam a trajetória dos profissionais da educação ao longo dos tempos, bem como a relação destes com as alterações ocorridas no âmbito do mundo do trabalho, pois "a natureza e identidade do trabalho docente devem ser pensadas como vivência concreta de relações sociais" (PASSOS, 2005, p.30).

Nesse intento, pode-se observar que 
a história mostra-nos que a mulher fora submetida, ao longo dos séculos, à negligência, aos estereótipos e a distorção dos próprios fatos históricos. Somente por meio do desenvolvimento da história social (Nova História) e do interesse crescente pelos acontecimentos locais e pela vida familiar e cotidiana das pessoas é que se procurou dar visibilidade às mulheres e à sua história, bem como às suas participações no contexto social como sujeitos de vontades, desejos e de projetos (CHAMON, 2005, p.58).

A formação da identidade do trabalhador docente foi influenciada por diversos aspectos e nosso objetivo é destacá-los para que seja possível a construção da imagem do professor atual e suas implicações na qualidade do ensino público.

Por outro lado, consideramos que a crescente precarização do trabalho docente (principalmente a partir de 1990) está vinculada às reformas educacionais promovidas no Brasil e nos demais países da América Latina. Nesse sentido, pode-se observar a ocorrência de uma reestruturação do trabalho pedagógico que amplia a precarização das relações de emprego e trabalho docentes e intensifica a insatisfação crescente dos trabalhadores docentes (OLIVEIRA, 2004).

\section{GÊNERO, CLASSE E EDUCAÇÃO ATÉ MEADOS DO SÉCULO XIX}

Desde o período colonial no Brasil, evidenciam-se as diferenças na prática social, econômica, política e educacional entre homens e mulheres.

A questão de gênero, isto é, a maneira como é assumida a diferença social entre homens e mulheres, já era constatada nesse período e utilizada como apoio para as desigualdades sociais.

Contudo, devemos abrir um parêntese para distinguir sexo e gênero, pois o primeiro refere-se à diferença biológica e o outro, ao contrário, remete a dimensão cultural, social e histórica que fundamenta a distinção e a relação entre masculino e feminino. Embora o gênero esteja relacionado aos dois sexos, este é utilizado em grande parte dos textos para se mencionar ao feminino.

No dizer de Chamon (2005, p.24), "a desigualdade de direitos entre senhores e escravos, homens e mulheres, não tem outra causa senão a lei do mais forte e interessava a elite dominante que permanecesse assim".

Assim, a elite disseminava ideologias e valores a favor dessa desigualdade, influenciando na definição de normas culturais e práticas sociais e tendo aceitação coletiva.

Nesse sentido, a caracterização da divisão do trabalho se configurou, ou seja, houve separação, hierarquização e polarização do trabalho, como citamos abaixo:

- Ao homem estava destinada a esfera produtiva e à mulher a reprodutiva;

- O trabalho masculino valia mais que o feminino, que era considerado improdutivo e não-material;

- As mulheres de camadas privilegiadas, que tinham a oportunidade de exercer uma atividade remunerada, tinham perspectiva de salários melhores que as da classe baixa.

Outra forma de disseminação de ideologias de classe e gênero aconteceu por intermédio da educação jesuítica, como cita Chamon (2005, p. 29): "o trabalho catequético, o apego aos dogmas e à autoridade, a prática de princípios morais e de subserviência e a negação de freqüência à escola pelo sexo feminino, formaram a base dos princípios em que se fundamentou a organização do ensino no Brasil". Assim, ao homem pobre era negado o direito a instrução e as mulheres cabiam somente os afazeres domésticos. 
Nesse período, o Estado não valorizava o ensino público e as escolas funcionavam em casas mal-estruturadas, em turmas multisseriadas, com péssimas condições físicas e de higiene e não contavam com muitos professores e nem materiais didáticos. Atendiam a uma clientela mínima ao qual ensinavam "a ler, escrever, contar, pouco de gramática e muito de religião" (MOURÃO, 1962, p.5 apud PEIXOTO \& PASSOS, 2005, p.14), bem como, a utilização sistemática das punições físicas através da palmatória e ou vara de marmelo.

Com o Ato Adicional de 1834, as Províncias do Brasil obtiveram maior autonomia em relação à instrução pública, ou seja, houve uma maior oferta e manutenção do ensino primário e uma preocupação crescente com a formação dos professores. Entretanto, a educação do povo não foi separada do seu contexto social, reforçando as desigualdades. Somente famílias privilegiadas puderam oferecer o ensino elementar a seus filhos através de preceptores masculinos. À mulher era negado o ensino das primeiras letras e as moças da elite tinham aulas de canto, de dança, de francês, de habilidades manuais e de ensino religioso, para preparar-lhes para o casamento.

O pensamento que dominava a época era que uma mulher bem-educada deveria aprender que a resignação e o silêncio lhe propiciariam estabilidade econômica e social no casamento.

Ao final de 1880, a monarquia estava enfraquecida frente às mudanças sociais que ocorriam: atritos com a Igreja Católica e com o exército, corrupção, aumento da população urbana, falta de apoio dos proprietários rurais, entre outros.

Nesse cenário, a escola pública e a profissão docente ganham espaço influenciado pelo ideário positivista de construir uma unidade nacional voltada para a modernidade e para o progresso.

Com a República Velha, período compreendido entre 1889 a 1930, o Brasil deu um salto na economia e isso culminou em mudanças políticas, sociais, educacionais e nas relações de trabalho.

Um dos ideais dos republicanos era possibilitar a educação das massas para moldar os cidadãos e controlar possíveis aspirações de classe. Nessa perspectiva, defendiam uma educação leiga e gratuita assumida pelo Estado. Com esse novo regime era enfatizado "o progresso pelo trabalho, a ordem pela disciplina, a educação como virtude" (PEIXOTO\& PASSOS, 2005, p.14).

\section{CAPITALISMO INDUSTRIAL, EDUCAÇÃO E TRABALHO}

Com o capitalismo industrial em expansão e com a urbanização das cidades, precisavam incorporar o povo à nação e qualificá-los para o mercado de trabalho e para consumir os produtos manufaturados, então, "cabia à escola contribuir tanto na produção quanto na reprodução social, visando fortalecer e legitimar as práticas culturais urbanas que interessavam às elites dominantes" (CHAMON, 2005, p.16).

Então, consolidaram a visão que a escola possibilitaria restaurar a moralidade e os bons costumes para os que ocupariam o novo mundo do trabalho e, assim, os preparariam para o exercício da cidadania.

Essas escolas reduziriam a distância entre a sociedade e a modernidade em ascensão e precisava de um povo preparado para a disciplina do trabalho. Os professores, nesse contexto, deveriam contribuir para o avanço da nação sem perturbar a sua ordem, ou seja, "era preciso de um corpo estável de profissionais que não buscasse no salário o motivo de seu ofício" (CHAMON, 2005, p. 80). O professor não tinha autonomia sobre o processo do seu trabalho. 
Sendo assim, o Estado passou a controlar a educação através da definição dos conteúdos, de normas disciplinares, de deveres aos alunos e professores, da matrícula e frequiência, dos exames, prêmios e castigos e da atribuição de funções e hierarquização do trabalho escolar, porque precisavam de uma organização escolar que atendesse aos ideais republicanos de reproduzir o modo de produção capitalista.

Como os homens tinham certo acesso à escolarização, foram agregados ao sistema de instrução pública como mestres-escola. Eles recebiam baixos salários, justificados pela desqualificação do seu saber (prático), trabalhavam em péssimas condições e não lutavam por melhorias porque o mercado de trabalho encontrava-se estagnado.

O magistério era a solução para o homem pobre nessa época, mas, com o tempo, os mesmos começaram a procurar trabalho no setor do comércio e nas indústrias em razão do desprestígio social pela profissão docente.

\section{A MULHER E A PROFISSÃO DOCENTE}

Na segunda metade do século XIX, houve uma formalização do ensino e do currículo com a Lei Orgânica do Ensino Normal (Decreto-Lei 8530/46), mas continuou sendo diferenciado por sexo, reforçando a discriminação.

Contudo, para colaborar na consecução dos ideais republicanos de organizar o poder, era preciso um trabalho filantrópico e também uma educação pública e gratuita a fim de ampliar a rede de ensino e o controle das massas. Além disso, a escola seria uma extensão do lar e da família que a classe média havia idealizando para a sociedade moderna.

Com a Constituição de 1891, a União passou a criar e controlar a instrução superior, secundária, primária e profissionalizante, contrariando a elite brasileira que queria que o povo continuasse iletrado e omisso.

Em todas as Províncias os homens foram abandonando a docência e as mulheres, que aceitavam os baixos rendimentos, as precárias condições de trabalho e o aumento da formação do magistério de 3 para 4 anos, bem como as que queriam sair da esfera doméstica, foram assumindo esse espaço.

Com o ideal de professora que leve mais cuidados maternos que intelectuais para a sala de aula e o aumento da procura de mulheres por essa profissão, foram criadas as condições para a feminização do magistério.

A partir de então o magistério se tornou um campo de trabalho feminino e no antigo primário (as quatro séries iniciais do $1^{\circ}$ grau) chegaram a perceber $70 \%$ do total de funcionários. Já em 1990, elas avançaram também para as séries finais do $1^{\circ}$ grau, para o $2^{\circ}$ grau e para os cargos de especialista: assistente de direção, direção e supervisão (REIS, 1993).

\section{PORCENTAGEM DE MULHERES NO MAGISTÉRIO (TOTAL PEA. BRASIL)}

\begin{tabular}{|l|c|c|}
\hline $\begin{array}{l}\text { Porcentagem de mulheres na PEA ocupadas no } \\
\text { magistério, por graus de ensino }\end{array}$ & $\mathbf{1 9 8 8}$ & $\mathbf{2 0 0 2}$ \\
\hline Ensino pré-escolar & 93,6 & 94,6 \\
\hline Ensino fundamental & 89,6 & 87,7 \\
\hline Ensino médio & 72,4 & 73,9 \\
\hline Ensino superior & 37,3 & 45,9 \\
\hline
\end{tabular}

Fonte: MTE/RAIS 1988 e 2002 
Esse fato contribuiu para o desprestígio social da profissão, mas a desvalorização não pode ser justificada pela feminização, já que a desvalorização da docência já vinha acontecendo quando era ocupada somente por homens (ALMEIDA, 1998).

As mulheres que lecionavam eram chamadas de leigas e os discursos dos positivistas apregoavam que estas deveriam ocupar o lugar dos homens do magistério, como uma extensão do papel de mãe, por seu altruísmo e superioridade moral e espiritual; instruindo as crianças com valores sociais e morais corretos. Na verdade, elas levariam para a sala de aula aspectos da vida no lar, do trabalho doméstico e da maternagem ${ }^{3}$ e passariam a ser vistas como segunda mãe ou tia.

O aspecto abordado acima clarifica ainda mais a divisão do trabalho por gênero, pois os homens separavam a vida privada da pública, sendo, por isso, considerados modelo de profissional e de proletário (objetivos, têm autoridade, produtivos, competitivos, racionais, possuem saberes técnicos). Já as mulheres, por articularem essas dimensões são consideradas desqualificadas, incompetentes e não profissionais porque alegam que essas qualidades são inatas e deixam de ser reconhecidas por essa qualificação informal que também é adquirida na socialização.

No entanto, os saberes e habilidades adquiridos no lar, a afetividade e a maternagem são importantes na resolução de problemas, na leitura de mundo e no cumprimento do seu trabalho educativo, mesmo não sendo percebido no cotidiano escolar pelo próprio professor ou pelos outros funcionários.

Com a argumentação de extensão do papel de mãe, conseguiriam atingir o ideal de trabalho filantrópico, ou seja, não seria preciso uma boa remuneração com o discurso de ser "uma missão digna para mulheres" (PIMENTA, 2001, p.29). Tratava-se, na verdade, de uma justificativa para terem uma mão-de-obra barata que não reivindicasse direitos e que acabou encontrando eco no imaginário popular, bem como, sendo socialmente desejável.

SALÁRIO MÉDIO DOS DOCENTES POR NÍVEL DE ENSINO (BRASIL - 2001)

\begin{tabular}{|l|l|}
\hline EDUCAÇÃO INFANTIL & 422,78 \\
\hline FUNDAMENTAL I (1 ${ }^{\mathrm{a}}$ a $4^{\mathrm{a}}$. SÉRIE) & 461,67 \\
\hline FUNDAMENTAL II (5 ${ }^{\mathrm{a}}$. A 8 $8^{\mathrm{a}}$. SÉRIE) & 599,85 \\
\hline ENSINO MÉDIO & 866,23 \\
\hline
\end{tabular}

Fonte: Pesquisa Nacional Amostra Domicílios PNAD- 2001.

A análise dos dados presentes na tabela acima reforçam a tese da desvalorização do trabalho feminino, pois os salários mais baixos correspondem aos níveis de ensino em que a presença da mulher é predominante.

Além disso, a mulher não era considerada cidadã, pois era proibida de votar, isto é, privada dos seus direitos políticos e assim, podiam ter uma vigilância e controle maior sobre elas (SANTOS, 2008).

Com esse pensamento, criaram um modelo de mulher para a escola e para a dimensão social e assim, a sociedade patriarcal cedeu um espaço à mulher no mercado de trabalho e a sua carreira profissional foi se encaminhando para o magistério com um discurso de "vocação" para a carreira. Porém, esse discurso serviu para "induzir as mulheres a escolher as profissões menos valorizadas socialmente" (BRUSCHINI \& AMADO, 1998, p.7) e se conformarem por não serem reconhecidas por essa dupla jornada combinada: o trabalho doméstico e o trabalho fora do lar.

As mulheres aceitavam essas condições, pois era uma oportunidade de darem continuidade aos seus estudos e possuírem um contato com o espaço público, que anteriormente só era possível com o casamento. 
Muitos homens pobres, nesse período, começaram a ver a feminização do magistério como uma chance de melhorar suas condições econômicas, porque somente essas mulheres trabalhavam e ganhavam salários, e casando-se com elas, essa remuneração somaria a sua renda.

Embora Comenius (2002), no século XVII, já tivesse discutido a necessidade de instrução de acordo com a necessidade do povo, somente nas três últimas décadas do século XIX que se criaram as Escolas Normais, inspiradas nas instituições francesas. Essas escolas também surgiram junto com o movimento republicano e não tinham uma política definida e unificada para o país e nem recursos, já que o Brasil encontrava-se ainda dividido em Províncias. A criação dessas escolas marca o processo de institucionalização da profissão docente no Brasil.

\section{FORMAÇÃO DOCENTE: AS ESCOLAS NORMAIS}

O currículo da Escola Normal dava continuidade à escola elementar, ou seja, caracterizava o ensino secundário, e formava para a moralização e para o exercício da obediência, já que "surgiu para cumprir uma função de classe não poderia desprezar a função moralizadora que também nascera com ela" (CHAMON, 2005, p.82). Além disso, as disciplinas sofriam uma separação de gênero como, por exemplo, Geometria era ministrada aos homens e Aritmética às mulheres.

Com relação à docência, essa mesma separação existia, pois somente homens lecionavam Geometria e ainda recebiam salários mais altos. Às mulheres restavam as disciplinas de habilidades manuais e estéticas.

O diploma do curso Normal passa a ser requisito para o ingresso no magistério, para concurso público, para o acesso à carreira, bem como permitia o ingresso no ensino superior, ou seja, passaram a ter mais rigor na caracterização da profissão docente. Contudo, o ensino superior era proibido às mulheres.

$\mathrm{O}$ ensino nessa escola funcionava em dois níveis $\left(1^{\circ}\right.$ e $2^{\circ}$ graus $)$ e o magistério primário era exercido nos grupos escolares e nas escolas normais pelas normalistas do ensino secundário.

Essas mulheres, que sempre foram silenciadas e excluídas, lecionavam nos centros urbanos, próximos de suas casas, conciliando, muitas vezes, o papel de mãe e de mestra. Até meados de 1930, a docência era o único emprego destinado às mulheres (SANTOS, 2008).

Por não aspirarem por mais que a sua condição permitisse, eram perfeitas para "inculcar, nas novas gerações, o amor ao dever, a idéia edificante do trabalho, da obediência à lei e do cultivo da moralidade" (CHAMON, 2005, p.94).

Além disso, o seu trabalho era submetido à fiscalização e controle masculino por meio da figura do inspetor e do diretor, indicados por políticos.

Com a Constituição de 1934, a mulher conquistou o direito ao voto, mas isso aconteceu após vários movimentos de luta e de resistência à exploração do seu trabalho e os homens sindicalistas por temerem que seus salários fossem ameaçados, passaram a ter postura separatista, repressora e discriminatória com o gênero oposto.

A partir da segunda metade da Revolução Industrial, construiu-se a idéia de salário mínimo para a família e muitas mulheres foram dispensadas ou tiveram seus salários rebaixados.

No período entre 1890 e 1971 a Escola Normal foi extinta e os cursos de formação de professores passaram a ser oferecidos por um curso médio para garantir-lhes um perfil profissional devido às exigências para exercer o magistério e dos concursos públicos. 
Entretanto, os avanços e recuos no campo de atuação profissional contribuíram para a desvalorização das professoras, que não podiam usufruir do provimento de cargos de carreira, já que os níveis mais elevados na escola eram constituídos por pessoas escolhidas por critérios políticos e não por já estarem inseridas e conhecerem a realidade escolar.

\section{REESTRUTURAÇÃO DO TRABALHO DOCENTE}

As reformas educacionais no Brasil, na década de 1990, se inserem na busca de adequação da educação ao "imperativo da globalização" (OLIVEIRA, 2004, p. 1129), onde prevalece uma intencionalidade de instrumentalização da educação no sentido de transformá-la em um mecanismo capaz de responder às demandas do capital, ou seja, a função da educação deveria restringir-se ao desenvolvimento de determinadas competências valorizadas no âmbito da produção (trabalho em equipe, iniciativa e flexibilidade, dentre outras) (HARVEY, 2003; SENNETT, Richard, 2001).

A reestruturação produtiva, característica da década de 1990 no cenário mundial, é uma tentativa de superação da crise do modelo fordista de produção que marca as décadas de 1970 e 1980. Nesse sentido as empresas buscam assegurar maior competitividade em um ambiente marcado pela mundialização do capital, da produção e dos mercados. As inovações organizacionais e tecnológicas constituem-se enquanto estratégias para a reversão da queda da taxa de lucros, onde as mudanças situam-se somente na superfície, já que, a lógica da acumulação capitalista permanece a mesma (ANTUNES, 2004).

Este contexto de reestruturação produtiva exige um novo perfil de trabalhador apto e adaptável às mudanças freqüentes no processo de trabalho (flexível) e detentor de uma sólida formação educacional calcada em novos modelos de competências condizente com os novos padrões tecnológicos e organizacionais. Tal mudança de paradigma implicou transformações substantivas nas condições de trabalho no cenário mundial e em especial no caso brasileiro (ANTUNES, 2004; CASTEL, 2001; HARVEY, 2003; HELOANI, 2003; SENNETT, 2001):

- Aumento do emprego precário, queda generalizada de salários, aumento do emprego informal/temporário (desassalariamento) e crescente taxa de desemprego, onde a empregabilidade se constitui enquanto uma categoria para encobrir tal realidade;

- Desregulamentação do mercado de trabalho e redução dos direitos sociais;

- O trabalhador passa a ser responsabilizado pela sua condição de desempregado e por sua inadequação às exigências do mercado de trabalho;

- Aumento dos níveis de escolarização simultâneo à precarização crescente do emprego;

- Contradição com a crença de que a utilização de uma força de trabalho mais escolarizada implicaria a melhoria das condições de trabalho;

- Permanência da centralidade do trabalho e eclosão de crises sócio-profissionais e identitárias do trabalhador flexível e precarizado;

- Aprofundamento do estranhamento no trabalho em que prevalece um aparente despotismo mais brando no atual estágio da sociedade produtora de mercadorias.

As mudanças nas políticas públicas de educação no Brasil, a partir da década de 1990, condizem com a realidade citada anteriormente e em grande medida dão sustentação à mesma. A Conferência mundial sobre Educação para Todos em Jontiem (1990 na Tailândia) é um marco para as reformas educacionais (OLIVEIRA, 2003, 2004):

- A educação deve responder às demandas do setor produtivo; 
- As concepções educacionais devem estar ancoradas nos princípios de equidade social (não mais igualdade), produtividade e redução do estado de pobreza e devem estar subordinadas à lógica da racionalidade econômica;

- A educação deve formar os indivíduos para a empregabilidade.

No debate dirigido pelo Banco Mundial e que se expressa por intermédio de seus relatórios ${ }^{4}$, enfatiza-se a necessidade de se reestruturar os serviços sociais (com destaque para a educação) visando aumentar a eficácia e a eficiência dos serviços. A pobreza é vista como uma ameaça ${ }^{5}$ e a educação torna-se um bem de consumo, uma mercadoria, um serviço e não um direito. Ao inserir a educação no campo dos serviços, como qualquer outro serviço público, pode-se terceirizá-la e privatizá-la.

As características - focalização dos gastos sociais, descentralização da gestão, privatização e desregulação das normas e legislação social - comuns à reforma do Estado no Brasil, também estão presentes nas recomendações para a redefinição das responsabilidades do Estado, elaboradas pelo Banco Mundial (1997). Vejamos como estas características se transmutam para o campo educacional:

- Focalização do gasto social no ensino básico, com ênfase no ensino fundamental de crianças e adolescentes;

- Descentralização que, no caso brasileiro, conforma-se através da municipalização do ensino fundamental;

- Privatização que, no caso brasileiro, não se realiza prioritariamente pela transferência de serviços públicos ao setor privado, mas pela constituição objetiva de um mercado de consumo de serviços educacionais;

- Desregulação, que se realiza pelo ajuste da legislação, dos métodos de gestão e das instituições educacionais às diretrizes anteriores e, re-regulamentação, através de instrumentos que assegurem ao governo central o controle do sistema educacional.

Segundo Oliveira (2004, p. 1130)

\begin{abstract}
Essa nova regulação repercute diretamente, na composição, estrutura e gestão das redes públicas de ensino. Trazem medidas que alteram a configuração das redes nos seus aspectos físicos e organizacionais e que têm se assentado nos conceitos de produtividade, eficácia, excelência e eficiência, importando, mais uma vez, das teorias administrativas as orientações para o campo pedagógico.
\end{abstract}

Nesse contexto a expansão da educação básica é marcada pela padronização e massificação de determinados processos administrativos, de planejamento, de gestão e pedagógicos que implicam maior responsabilização dos professores e maior envolvimento da comunidade. Desta maneira amplia-se de um lado, as funções/atribuições dos professores, onde esses profissionais passam a desempenhar funções de assistente social, enfermeiro, médico, psicólogo, entre outras (OLIVEIRA, 2004) e intensifica-se de outro lado, o sentimento de "desprofissionalização, de perda de identidade profissional, da constatação de que ensinar às vezes não é o mais importante" (OLIVEIRA, 2004, p. 1132).

\title{
PRECARIZAÇÃO DO TRABALHO DOCENTE:
}

As políticas educacionais neoliberais implementadas no Brasil evidenciam uma nova concepção de educação e ao mesmo tempo, repercutem negativamente sobre o trabalho docente nos aspectos concernentes às relações de emprego. $\mathrm{O}$ rebaixamento salarial e o aumento do número de professores com contratos temporários ${ }^{6}$ exemplificam a 
precarização crescente que marcam a realidade a que estão submetidos os professores das redes públicas de ensino.

Essa nova regulação assenta nos paradigmas que orientam a atuação das empresas que sobrevivem e crescem no mercado mundializado, onde a busca incessante pela maximização dos lucros se viabiliza pelo incremento da eficiência, produtividade e competitividade.

O Banco Mundial influenciou, de forma significativa, a definição das políticas educacionais no Brasil, não só como fonte financiadora externa de recursos para a educação pública, mas como formulador das mesmas:

A análise econômica aplicada à educação se centra na comparação entre os benefícios e os custos, para as pessoas e para a sociedade (...). A técnica mais eficaz é aquela que produz o resultado desejado a um custo mínimo e que resulte no aumento do rendimento escolar a um custo determinado (...). Os benefícios de financiamento para melhorar a eficiência da educação, por exemplo, mediante o uso mais intensivo do pessoal docente e dos prédios escolares se expressam normalmente em termos de redução dos custos unitários por estudante ou por egresso (BANCO MUNDIAL, 1996, p. 105, 108).

Nessa perspectiva o professor passa a ser entendido, enquanto um, entre diversos insumos, portanto há que se combinarem eficientemente os diferentes insumos ${ }^{7}$ no sentido de se garantir um 'ensino eficaz'.

A relação professor-aluno é uma medida global de eficiência pessoas. As escolas dos países de baixa e média renda poderiam diminuir custos e melhorar a aprendizagem aumentando o coeficiente professor-aluno. Utilizariam menos mestres e poderiam transferir recursos para outros insumos que melhoram o rendimento, como livros didáticos e a formação de professores em serviço. As possibilidades de melhorar a eficiência através de um modesto aumento do coeficiente professor-aluno são enormes, porque os gastos com pessoal docente normalmente representam cerca de dois terços do gasto em educação (BANCO MUNDIAL, 1996, p. 64).

A crescente precarização das condições do trabalho docente, discutidas anteriormente, provocam altos índices de absenteísmos, acúmulo de empregos (duas ou mais escolas, número restrito de trabalhadores qualificados e queda da qualidade dos serviços públicos (educação escolar) oferecidos à população.

As profissões representam formas históricas de organização social e de categorização das atividades do trabalho que evidenciam relações políticas, sobretudo com o Estado. Significam também formas históricas de seu exercício, de identificação subjetiva dos seus membros, de expressão dos valores de ordem ética, plena de significações culturais. As profissões representam também contradições e tensões entre as diferentes instituições e sujeitos envolvidos, que procuram, assegurar o trabalho, salários condizentes e estáveis, trabalho e ou empregos reconhecendo sua expertise e direitos sociais vinculados ao trabalho. As relações econômicas evidenciam a relação entre profissão e mercado, indagam pelo seu futuro, dentro de uma economia de mercado, cada vez mais racionalizada e mundializada (DUBAR \& TRIPIER, 1998, P. 13). 


\section{CONSIDERAÇÕES FINAIS}

O contexto da reestruturação produtiva (anos 80) é caracterizado pela precarização do trabalho e conseqüentemente da vida das pessoas, principalmente as camadas mais discriminadas, seja por gênero, raça e condições econômicas.

Muitos fatores como a falência dos serviços públicos, diminuição da taxa de fertilidade, conjunturas econômicas desfavoráveis e transformações sociais e culturais contribuíram para o aumento da PEA feminina no Brasil no período compreendido entre 1970 e 1990

A partir dos anos 90, a taxa de escolaridade feminina também aumentou em relação à masculina e alcançaram níveis elevados, mas concentrados em áreas como turismo, letras, artes, ciências biológicas, humanas e saúde.

Todos esses acontecimentos abordados, anteriormente, contribuíram para a formação da identidade da mulher como professora, ocultando suas outras habilidades adquiridas no espaço privado do lar ou intelectualmente.

As mulheres ainda hoje recebem salários menores que os homens, ocupam espaços inferiores e subordinados ao trabalho masculino (secretárias, recepcionistas, professoras primárias, vendedoras, empregadas domésticas) e não possuem carteira assinada. No dizer de Ludke \& Boing (2004, p. 1160) “a 'profissão' docente exibe, mesmo aos olhos do observador comum, sinais evidentes de precarização, visíveis pela simples comparação com datas passadas".

A segmentação do mercado de trabalho enuncia desigualdades nas relações de gênero e cria "guetos" femininos, ou seja, determinadas profissões como, por exemplo, a profissão docente, tornaram-se eminentemente femininas e marcadas pela precariedade das condições de trabalho e do crescente desprestígio social. afirma que

A respeito das condições de trabalho, que caracterizam trabalho docente, Leite

Um grave processo de precarização das condições de vida e de trabalho, bem como de exclusão social, acompanha a reestruturação produtiva a partir dos anos 80, mas, sobretudo a partir das políticas macroeconômicas colocadas em prática com a abertura do mercado nos anos 90. Marcado por profundas desigualdades de gênero, raça e idade, esse processo afeta desigualmente homens e mulheres, brancos e negros, jovens e adultos, punindo especialmente os setores mais discriminados (2003, p. 143).

A reestruturação do trabalho docente, marcada pela crescente precarização das condições de trabalho, tem implicações diretas no chão da escola. Nesse sentido, a discussão acerca da melhoria da qualidade da educação pública no Brasil, deve considerar os aspectos que dizem respeito ao salário dos professores e as demais condições de trabalho a que os mesmos estão submetidos. Dito de outra forma: não existe política educacional exitosa em que $35 \%^{8}$ dos professores efetivos da rede pública estejam afastados por licença médica. A partir de um levantamento preliminar constamos que a quase totalidade das doenças que motivaram os afastamentos tem origem psicológica que se origina na dupla ou tripla jornada de trabalho e na ampliação das atribuições do cotidiano na escola. Acreditamos ser necessária a ampliação do número de pesquisas que analisem a nova conformação do trabalho docente e suas implicações, pois a organização social das atividades de trabalho, sua significação subjetiva e os modos de estruturação do 
trabalho devem se constituir no núcleo de análise sobre a educação e a profissão docente no Brasil.

\section{REFERÊNCIAS BIBLIOGRÁFICAS}

ALMEIDA, Jane Soares de. Mulher e educação: a paixão pelo possível. São Paulo, UNESP, 1998.

ANTUNES, Ricardo. As mutações no mundo do trabalho na era da mundialização do capital. Educação \& Sociedade, Campinas, vol. 25, no. 87, p. 335-351, 2004.

BANCO MUNDIAL. O trabalhador e o processo de integração mundial. Relatório sobre o desenvolvimento mundial. Washington, 1995.

Do plano ao mercado. Relatório sobre o desenvolvimento

mundial. Washington, 1996.

O Estado num mundo em transformações. Relatório sobre o desenvolvimento mundial. Washington, 1997.

BOING, Luiz Alberto \& LUDKE, MENGA. Caminhos da profissão e da profissionalidade docente. Educação \& Sociedade, Campinas, vol. 85, no. 89, p. 11591180, 2004.

BRUSCHINI, Cristina \& AMADO, Tina. Estudos sobre mulher e educação. Algumas questões sobre o magistério. Cadernos de Pesquisa, São Paulo, Fundação Carlos Chagas, no. 64 , p. 04-13, 1988.

CARVALHO, Marília Pinto de. Trabalho docente e relações de gênero. Algumas indagações. Revista Brasileira de Educação, ANPED, no. 2, p. 77-84, 1996.

CASTEL, Robert. As metamorfoses da questão social: uma crônica do salário. Petrópolis, Vozes, 2001.

CHAMON, Magda. Trajetória de feminização do magistério. Ambigüidades e conflitos. Belo Horizonte, Autêntica, 2005.

COMENIUS, Johann Amos. Didática magna. São Paulo, Martins Fontes, 2002.

DUBAR, Claude \& TRIPIER, Pierre. Sociologie des professions. Paris, Armand Colin, 1998.

HARVEY, David. Condição pós moderna: uma pesquisa sobre as origens da mudança cultural. São Paulo, Loyola, 2003.

HELOANI, Roberto. Gestão e organização no capitalismo globalizado. História da manipulação psicológica no mundo do trabalho. São Paulo, Atlas, 2003. 
IBGE. PNAD. http://www.ibge.gov.br/trabalhoerendimento/pnad2004/notas_pnad.pdf, acesso em 02/10/2008.

LEITE, Márcia de Paula. Trabalho e sociedade em transformação: mudanças produtivas e atores sociais. São Paulo, Fundação Perseu Abramo, 2003.

MTE/RAIS. http://www.mte.gov.br, acesso em 02/10/2008.

LICHTENSZTEJN, Samuel \& BAER, Mônica. Fondo Monetário Internacional y Banco Mundial. Estratégias y politicas del poder financeiro. San José, Buenos Aires, Nueva Sociedad, 1986.

OLIVEIRA, Dalila Andrade. As reformas educacionais na América Latina e os trabalhadores docentes. Belo Horizonte, Autêntica, 2003.

A reestruturação do trabalho docente: precarização e

flexibilização. Educação \& Sociedade, Campinas, vol. 25, no. 89, p. 1127-1144, 2004.

PASSOS, Mauro. Historiando embates e conquistas da profissão docente em Minas Gerais (1977-2004). In: PEIXOTO, Ana Maria Cassandra \& PASSOS, Mauro. A escola e seus atores - educação e profissão docente. Belo Horizonte, Autêntica, 2005.

PIMENTA, Selma Garrido. O estágio na formação de professores: unidade teoria e prática? São Paulo, Cortez, 2001.

REIS, Maria Cândida Delgado. Tessitura de destino: mulheres e educação. São Paulo, EDUC,1993.

SANTOS, Elizabeth Ângela dos. Profissão docente: uma questão de gênero? http://www.fazendogenero8.ufsc.br/sts/ST8/Elizabeth_Angela_dos_Santos_08.pdf, acesso em 06/10/2008.

SENNETTR, Richard. A corrosão do caráter. Consequências pessoais do trabalho no novo capitalismo. São Paulo, Record, 2001.

SOUSA, Érica Renata de. No coração da sala de aula: gênero e trabalho docente nas séries iniciais. Cadernos Pagu, Campinas, no. 17/18, p. 379-387, 2001/02.

\footnotetext{
${ }^{1}$ Doutor em Educação pela Universidade Estadual de Campinas e professor da Universidade Federal de Mato Grosso; Instituto de Educação; Departamento de Teoria e Fundamentos da Educação.

${ }^{2}$ Discente do $4^{\circ}$. ano do curso de Pedagogia da Universidade Federal e Mato Grosso; Bolsista do Projeto PES.

${ }^{3}$ A maternidade é o processo biológico que a mulher passa ao gerar uma criança e na maternagem a mulher dá a assistência (psicoafetiva e sócio-cultural) necessária para a vida em sociedade (cuidados maternos, formação de hábitos, valores e atitudes).
}

Revista HISTEDBR On-line, Campinas, $n$. Especial, p 251-263, mai.2009 - ISSN: 1676-2584 262 
4 O trabalhador e o processo de integração social (1995), Do plano ao mercado (11996) e O Estado num mundo em transformação (1997).

5 "Por definição, as necessidades básicas são sempre críticas, e os governos ajudam as pessoas pobres a satisfazê-las não por questão de filantropia, mas pelo prudente investimento em formação de capital humano. Certamente, o que é muito mau para a economia é permitir que o cultivo da pobreza cresça e se difunda no seio de uma nação em tal medida que comece a infectar e erodir toda a trama social" (MC NAMARA, apud LICHTENSZTEJN \& BAER, 1986, P. 125).

${ }^{6}$ Segundo dados informados pela SEDUC-MT, 45\% dois professores da rede estadual, em 2008, são temporários.

7 Os insumos, considerados pelo Banco Mundial, como importantes para a melhoria da qualidade da educação são: merenda e saúde escolar, espaço físico, livro didático, formação de professores, currículos escolares, professor, tempo de aprendizagem e as tecnologias de ensino e aprendizagem (Banco Mundial, 1996).

${ }^{8}$ Dados fornecidos pela SEDUC-MT.

Artigo recebido em: 05/11/2008

Aprovado para publicação em: 20/11/2008 